\title{
PENGEMBANGAN MODEL COOPERATIVE LEARNING UNTUK PENDIDIKAN TINGGI
}

\author{
Nurlaila \\ Email: nurlaila@iainbatusangkar.ac.id
}

\begin{abstract}
Abstrak:
Penelitian ini bertujuan untuk mengembangkan model cooperative learning untuk pendidikan tinggi. Model cooperative learning dipilih karena model pembelajaran ini tidak hanya menekankan pada pencapaian hasil belajar secara akademik tetapi juga mengembangkan kompetensi sosial mahasiswa, sehingga penggunaannya sangat tepat untuk pembelajaran pada pendidikan tinggi. Metode penelitian yang digunakan adalah metode R\&D (Research and Development). Hasil penelitian ini berupa model cooperative learning untuk pendidikan tinggi yang menerapkan prinsip-prinsip cooperative learning dalam menentukan Rencana Pembelajaran Semester (RPS), Satuan Acara Perkuliahan (SAP), materi perkuliahan, alat evaluasi, peran dan tanggung jawab mahasiswa dan dosen, struktur kelompok dan struktur tugas. Dalam praktiknya, penerapan cooperative learning dalam perkuliahan mengharuskan kesiapan segala perangkat yang mendukung, baik perangkat keras maupun perangkat lunak. Kemampuan dosen, partisipasi mahasiswa, ketersediaan sumber belajar, dan kelengkapan sarana pendukung merupakan halhal pokok untuk penerapan cooperative learning pada pendidikan tinggi.
\end{abstract}

\begin{abstract}
:
This study aims to develop a cooperative learning model for higher education. The cooperative learning model was chosen because this learning model not only emphasizes the achievement of academic learning outcomes but also develops student social competence, so that its use is very appropriate for learning in higher education. The research method used is the R\&D (Research and Development) method. The results of the study are in the form of cooperative learning models for higher education that apply cooperative learning principles in determining Semester Learning Plans (RPS), Lecture Program Units (SAP), lecture material, evaluation tools, roles and responsibilities of students and lecturers, group structure and task structure. In practice, the application of cooperative learning in lectures requires the readiness of all devices that support, both hardware and software. The ability of lecturers, student participation, the availability of learning resources, and the completeness of supporting facilities are the main things for implementing cooperative learning in higher education.
\end{abstract}

Kata kunci:

Coopertive Learning, Kompetensi Sosial, Pendidikan Tinggi

How to Cite: Nurlaila. (2019). Pengembangan Model Cooperative Learning untuk Pendidikan Tinggi. Lentera Pendidikan : Jurnal Ilmu Tarbiyah dan Keguruan, 22(2), 213-222. 


\section{PENDAHULUAN}

Pendidikan tinggi tidak hanya membangun kompetensi akademik tetapi juga kompetensi sosial. Rancangan Permendikbud RI tentang Standar Nasional Pendidikan Tinggi (SNPT) Pasal 8 (1) menyiratkan bahwa kompetensi sosial merupakan salah satu komponen capaian pembelajaran minimal aspek sikap dan tata nilai dalam Standar Kompetensi Lulusan (SKL) pendidikan tinggi. Menurut Nangle, Grover, Holleb, Cassano, \& Fales (2010) kompetensi sosial adalah kemampuan untuk mencapai tujuan personal dalam interaksi sosial sekaligus memelihara hubungan positif dengan orang lain dari waktu ke waktu dan semua situasi.

Pengembangan kompetensi sosial ini sangat penting bagi mahasiswa. Hasil penelitian menunjukkan bahwa keterampilan sosial mahasiswa dan perilaku dalam situasi sosial selama masa studi di perguruan tinggi berkontribusi pada keberhasilan mereka dalam menempuh masa transisi menuju dunia kerja. Strategi sosial yang diadopsi selama studi perguruan tinggi juga berdampak pada komitmen kerja dan menghadapi awal karirnya di dunia kerja tersebut (Nauert, 2011). Oleh karena itu, pendidikan pada perguruan tinggi diharapkan dapat mengembangkan kompetensi akademik dan kompetensi sosial secara seimbang. Kedua kompetensi ini terdapat dalam model pembelajaran kooperatif. Pembelajaran kooperatif ini mencakup suatu kelompok kecil siswa yang bekerja sebagai sebuah tim untuk menyelesaikan suatu masalah, menyelesaikan suatu tugas atau mengerjakan sesuatu untuk mencapai tujuan pembelajaran dan hasil belajar (Rahmadani, Tayeb, \& Baharuddin, 2018: 25).

Menurut Abdurrahman dalam Manullang, Rahmadana, \& Putriku (2017) menyatakan bahwa pembelajaran kooperatif adalah pembelajaran yang secara sadar dan sistematis mengembangkan interaksi yang silih asah, silih asih dan silih asuh antara sesama mahasiswa sebagai latihan hidup di dalam masyarakat nyata. Sedangkan menurut Kurnia, Ruskan, \& Ibrahim (2014: 646) cooperative learning merupakan strategi pengajaran yang dirancang untuk mendidik mahasiswa dalam bekerja sama kelompok dan interaksi antar mahasiswa. Arends \& Kilcher (2010) menjelaskan bahwa tujuan cooperative learning adalah dua aspek yaitu aspek kognitif dan aspek sosial. Tujuan tersebut digambarkan sebagai berikut.

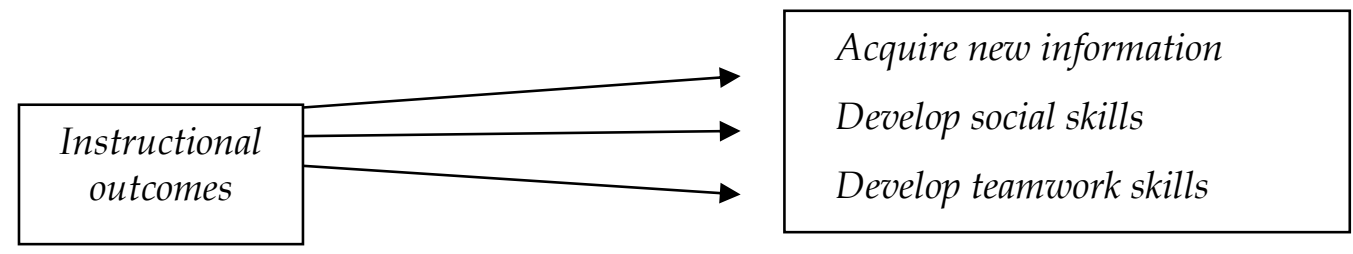

Gambar 1. Instructional Outcomes for Cooperative Learning

Dengan demikian, dapat ditegaskan bahwa cooperative learning sangat tepat digunakan untuk pendidikan tinggi, karena tidak hanya mengembangkan kompetensi akademik mahasiswa tetapi juga dapat mengembangkan kompetensi sosialnya sehingga dapat memenuhi Standar Kompetensi Lulusan (SKL) pendidikan tinggi sebagaimana yang digariskan dalam Standar Nasional Pendidikan Tinggi (SNPT), 
cooperative learning akan membantu mahasiswa untuk mengembangkan sejumlah keterampilan sosial sekaligus melatih sikap sosial mereka melalui kerjasama. Penggunaan strategi cooperative learning pada pendidikan tinggi juga didukung oleh pendapat pakar, di antaranya Basta (2011) yang mengemukakan bahwa cooperative learning adalah sebuah pendekatan yang dapat diterapkan, baik pada pendidikan dasar dan menengah, maupun pada pendidikan tinggi.

Marashi \& Baygzadeh (2010) mengemukakan beberapa perspektif yang diasosiasikan dengan pembelajaran kooperatif. Salah satunya adalah pandangan konstruktivis sosial oleh Vygotsky. Menurut Vygotsky, belajar merupakan hasil dari interaksi sosial yang mendorong ke arah perkembangan kognitif. Di samping itu, terdapat perspektif Piaget yang berkaitan dengan pembelajaran kooperatif, yaitu konstruktivis personal. Suatu komponen sentral dari teori perkembangan oleh Piaget tentang belajar dan berpikir bahwa belajar dan berpikir melibatkan partisipasi peserta didik. Pengetahuan bukan hanya ditransmisikan secara lisan tetapi harus dibangun dan direkonstruksi oleh peserta didik. Lebih lanjut, Piaget menegaskan bahwa bagi seorang anak untuk mengetahui dan mengkonstruksi pengetahuan tentang dunia, ia harus bertindak pada objek dan tindakan inilah yang memberikan pengetahuan tentang objek tersebut.

Kedua teori dari Vygotsky dan Piaget ini saling melengkapi, teori pertama dari Vygotsky mengusung pentingnya interaksi sosial dalam belajar, sedangkan teori yang kedua dari Piaget menganjurkan pembelajaran aktif yang melibatkan partisipasi peserta didik. Keduanya adalah elemen penting dalam merealisasikan pembelajaran kooperatif bagi peserta didik di dalam kelas.

Menurut Richards \& R. Schmidt (2010), co-operation dalam konteks pembelajaran adalah bekerjasama dengan satu atau lebih teman untuk menyelesaikan suatu masalah, menyelesaikan tugas pembelajaran, membagi informasi atau memperoleh feedback. Marashi \& Baygzadeh (2010) mengemukakan bahwa elemen-elemen pembelajaran kooperatif terdiri dari positive interdependence, individual accountability, quality of group interaction, teaching interpersonal and small group skills, dan teaching social skills.

Pembelajaran kooperatif dapat dilaksanakan melalui berbagai macam metode. Shaaban \& Ghaith (2005) mengemukakan beragam metode pembelajaran kooperatif, sejarahnya, dan pengembangnya, ditunjukkan pada tabel 1 berikut.

Tabel 1. Modern Methods of Cooperative Learning

\begin{tabular}{lll}
\hline \multicolumn{1}{c}{$\begin{array}{c}\text { Researcher } \\
\text { Developer }\end{array}$} & \multicolumn{1}{c}{ Date } & \multicolumn{1}{c}{ Method } \\
\hline Johnson E Johnson & Mid 1970s & Learning Together \\
\hline DeVries E Edward & Early 1970s & Teams-Games- Tournaments (TGT) \\
\hline Sharan E Sharan & Mid 1970s & Group Investigation (GI) \\
\hline Johnson E Johnson & Late 1970s & Constructive Controversy (CC) \\
\hline $\begin{array}{l}\text { Aronson, Blaney, Sikes, } \\
\text { Stephan E Snapp; Slavin }\end{array}$ & Late 1970s & Jigsaw Procedure \\
\hline Slavin & Late 1970s & Student Teams-Achievement Divisions (STAD) \\
\hline
\end{tabular}




\begin{tabular}{lll}
\hline Cohen & Early 1980s & Complex Instruction (CI) \\
\hline Slavin, Leavey, E Madden & Mid 1980s & Team Accelerated Instruction (TAI) \\
\hline Kagan & Mid 1980s & Cooperative Learning Structures \\
\hline Stevens, Madden, & Mid 1980s & Curriculum Packages: Cooperative Integrated \\
Slavinn, E Farnish & & Reading and Composition (CIRC) \\
\hline
\end{tabular}

Dalam menerapkan pembelajaran kooperatif, harus memiliki perencanaan yang matang. Kagan (2009), mengemukakan The Seven Keys pembelajaran kooperatif yang digambarkan sebagai berikut.

Tabel 2. The Seven Keys

\begin{tabular}{ll}
\hline Key 1. Structures & How to use cooperative learning instructional strategies \\
\hline Key 2. Teams & How and when to form and re-form the various types of teams \\
\hline Key 3. Management & How to manage the cooperative classroom \\
\hline Key 4. Classbuilding & How to create a caring, cooperative community of learners \\
\hline Key 5. Teambuilding & How to develop powerful learning teams \\
\hline Key 6. Social Skills & How to develop students' ability to cooperate \\
\hline $\begin{array}{l}\text { Key 7. Basic Principles } \\
\text { (PIES) }\end{array}$ & \\
\hline
\end{tabular}

Sejalan dengan gagasan tersebut, Arends \& Kilcher (2010) juga mengemukakan langkah-langkah perencanaan pembelajaran kooperatif, yaitu: (1) memilih tipe pembelajaran kooperatif yang akan digunakan, karena setiap pendekatan pembelajaran kooperatif memberikan beberapa karakteristik umum, namun masingmasing memiliki langkah-langkah yang berbeda; (2) memilih tujuan dan konten pelajaran, yaitu memilih fokus konten akademik dan keterampilan-keterampilan sosial yang akan diajarkan; (3) pengelompokan peserta didik secara heterogen, sebaiknya dimulai dengan kelompok sederhana yang terdiri dari 4 atau 3 orang, kemudian dikelompokkan 4-6 orang, sehingga menjadi ukuran ideal; (4) mengumpulkan dan mengorganisir peserta didik untuk berdiskusi dengan teman kelompoknya, (5) mengorganisir lingkungan belajar dan guru memfasilitasi kerja kelompok.

Terkait dengan evaluasi dalam pembelajaran kooperatif, maka aspek akademik dan aspek sosial penting untuk dinilai. Dalam pembelajaran kooperatif bisa dilakukan self-assessment (penilaian diri), peer assessment (penilaian sejawat), dan teacher assessment (penilaian guru), dan sebagainya. Banyak strategi penilaian seperti paper-and pencil tests, observasi, checklist, rubrik, dan evaluasi kelompok juga dapat digunakan untuk menilai hasil belajar pembelajaran kooperatif (Arends \& Kilcher, 2010).

Dornyei \& Murphey dalam Apple (2006) mengemukakan bahwa perubahan peserta didik dipengaruhi oleh peran guru di kelas. Menurut Arends \& Kilcher (2010), peran guru dalam pembelajaran kooperatif adalah sebagai fasilitator, pelatih, dan pemandu. Guru menyiapkan bahan bagi siswa untuk digunakan membimbing dalam kelompok, dan memastikan tanggung jawab individu dan kelompok. Tanggung jawab utama pengajaran adalah untuk membangun lingkungan dan struktur sosial kooperatif yang akan membantu peserta didik belajar keterampilan sosial dan kerja sama tim, serta keterampilan memecahkan masalah dan resolusi konflik. Sedangkan 
peran peserta didik adalah menjadi peserta aktif dan diharuskan untuk terlibat penuh dalam kerja kelompok. Keterampilan kelompok dalam hal mendengar, berdiskusi, dan mengemukakan pendapat diperlukan untuk kesuksesan kelompok pembelajaran kooperatif. Keterampilan membaca, meneliti, menulis, dan presentasi juga diperlukan untuk menyelesaikan tugas-tugas yang diberikan.

Cooperative learning memiliki beberapa karaktersitik dan salah satunya adalah bahwa setiap kelompok dalam cooperative learning terdiri dari peserta didik dengan kapasitas dan kemampuan yang berbeda-beda (Thu'aimah \& Al-Naqah, 2006). Mereka juga belajar untuk lebih menerima keragaman dan lebih toleran terhadap perbedaan. Oleh karena itu, penulis tertarik melakukan penelitian yang bertujuan untuk mengembangkan model cooperatiflearning untuk pendidikan tinggi.

\section{METODE PENELITIAN}

Jenis penelitian yang digunakan adalah Research and Development. Penelitian dimulai dengan tahap studi pendahuluan berupa kajian literatur dan kajian lapangan. Hasil studi pendahuluan dijadikan sebagai dasar dalam pengembangan model pembelajaran cooperative learning untuk pendidikan tinggi. Model yang dikembangkan selanjutnya divalidasi dan direvisi sehingga menghasilkan model akhir sebagai produk pengembangan.

\section{HASIL DAN PEMBAHASAN}

Berdasarkan studi pendahuluan melalui penelusuran literatur penulis menemukan beberapa alasan tepatnya cooperative learning digunakan untuk pembelajaran pada pendidikan tinggi. Pertama, cooperative learning adalah pembelajaran yang berpusat pada mahasiswa, sedangkan dosen berperan sebagai fasilitator yang akan memfasilitasi mahasiswa agar dapat memperoleh pengetahuan dan keterampilan melalui kelompok kooperatif tersebut. Undang-Undang RI No. 12 tahun 2012 tentang Pendidikan Tinggi pasal 6 menjelaskan bahwa salah satu prinsip pendidikan tinggi adalah pembelajaran yang berpusat pada mahasiswa dengan memperhatikan lingkungan secara selaras dan seimbang, pembelajaran berpusat pada mahasiswa (learner-centred approach). Kedua, cooperative learning menghargai perbedaan individu mahasiswa dan memberikan kesempatan yang sama untuk belajar dalam kelompoknya. Ketiga, cooperative learning dapat menciptakan suasana yang menyenangkan karena adanya interaksi yang baik antara sesama mahasiswa. Keempat, cooperative learning dapat mendorong mahasiswa agar memiliki keinginan yang kuat dari dalam dirinya untuk mengikuti perkuliahan, bukan hanya menganggap perkuliahan sebagai suatu rutinitas semata. Kelima, cooperative learning dapat mendorong mahasiswa memiliki kemandirian dalam perkuliahan tersebut, yaitu berupaya menyelesaikan sendiri tugas-tugasnya tanpa mengandalkan orang lain. Keenam, cooperative learning dapat mengembangkan aspek kognitif dan aspek sosial sekaligus. Ketujuh, cooperative learning memiliki berbagai macam metode yang bisa digunakan untuk pembelajaran dalam setiap mata kuliah. 
Di samping melakukan penelusuran literatur, peneliti juga melakukan pengamatan terhadap fakta-fakta lapangan terkait dengan pembelajaran pada pendidikan tinggi. Pengamatan dilakukan pada tiga jurusan di Fakultas Tarbiyah Institut Agama Islam Negeri Batusangkar tahun pelajaran 2018/2019. Berdasarkan hasil pengamatan tersebut, peneliti menemukan alasan mengapa cooperative learning tepat digunakan untuk pembelajaran pada pendidikan tinggi.

Pertama, cooperative learning adalah model kerja kelompok yang tepat bagi mahasiswa karena model kerja kelompok ini dapat mengaktifkan seluruh mahasiswa. Kemudian diperkuat oleh Lestari (2008: 146-147) menyatakan bahwa model pembelajaran ini juga memberi kesempatan kepada mahasiswa untuk bekerja sama dengan sesama mahasiswa dalam tugas-tugas yang terstruktur. Selain itu, alur proses belajar tidak harus berasal dari dosen menuju mahasiswa tetapi mahasiswa bisa juga saling mengajar dengan sesama mahasiswa lainnya. Perkuliahan dengan sistem kerja kelompok yang berlangsung selama ini pada Perguruan Tinggi belum efektif, karena hanya sebagian anggota kelompok atau bahkan satu atau dua orang saja yang ikut berperan serta dalam kerja kelompok tersebut, sedangkan anggota kelompok yang lain hanya sebagai anggota yang pasif. Akibatnya hanya sebagian mahasiswa yang mendapatkan manfaat dari kerja kelompok tersebut sedangkan yang lainnya tidak mendapatkan manfaat sama sekali. Implikasi lebih jauh adalah tidak tercapainya kompetensi kognitif sebagaimana yang diharapkan dalam kurikulum. Untuk itu, penerapan model cooperative learning sangat diperlukan, yaitu suatu model kerja kelompok yang dapat mengaktifkan seluruh anggota kelompok.

Kedua, cooperative learning dapat mengatasi kesulitan dosen ketika harus mengajar mahasiswa dengan tingkat kemampuan yang berbeda-beda, karena kelompok kooperatif terdiri dari mahasiswa dengan kemampuan yang berbeda-beda dan kelompok kooperatif mengakomodir perbedaan tersebut. Sebagaimana diketahui, input mahasiswa pada Perguruan Tinggi beragam, yaitu berasal dari latar belakang pendidikan yang berbeda, seperti Sekolah Menengah Atas (SMA), Madrasah Aliyah (MA), Sekolah Menengah Kejuruan (SMK), dan pesantren, dengan peminatan yang berbeda-beda pula. Dengan latar belakang pendidikan mahasiswa yang berbeda-beda dalam satu kelas, maka mereka memiliki kemampuan yang berbeda-beda pula. Oleh karena itu, cooperative learning adalah solusi yang tepat untuk mengatasi kesulitan dalam pembelajaran peserta didik yang memiliki kemampuan berbeda-beda.

Berdasarkan studi pendahuluan tersebut, maka dikembangkan model cooperative learning untuk pendidikan tinggi. Model cooperative learning yang dikembangkan dilandasi oleh filsafat konstruktivisme yaitu konstruktivis personal dari Piaget dan dan konstruktivis sosial dari Vygogtsky. Model cooperative learning menggunakan pendekatan learner-centred approach, yaitu pembelajaran yang berpusat pada mahasiswa sebagai partisipan yang aktif belajar melalui interaksi sosial, sedangkan dosen berperan sebagai fasilitator. Dalam cooperative learning ini dosen dapat memilih salah satu di antara beberapa metode kooperatif seperti Learning Together, TGT, GI, CC, Jigsaw, STAD, CI, TAI, CLS, atau CIRC, tergantung pada karakteristik materi pada mata 
kuliah yang diampu. Hasil yang diharapkan dari perkuliahan menggunakan cooperative learning ini adalah agar mahasiswa memiliki kompetensi kognitif dan kompetensi sosial sekaligus.

Model cooperative learning untuk pendidikan tinggi tersebut dapat diilustrasikan sebagai berikut:

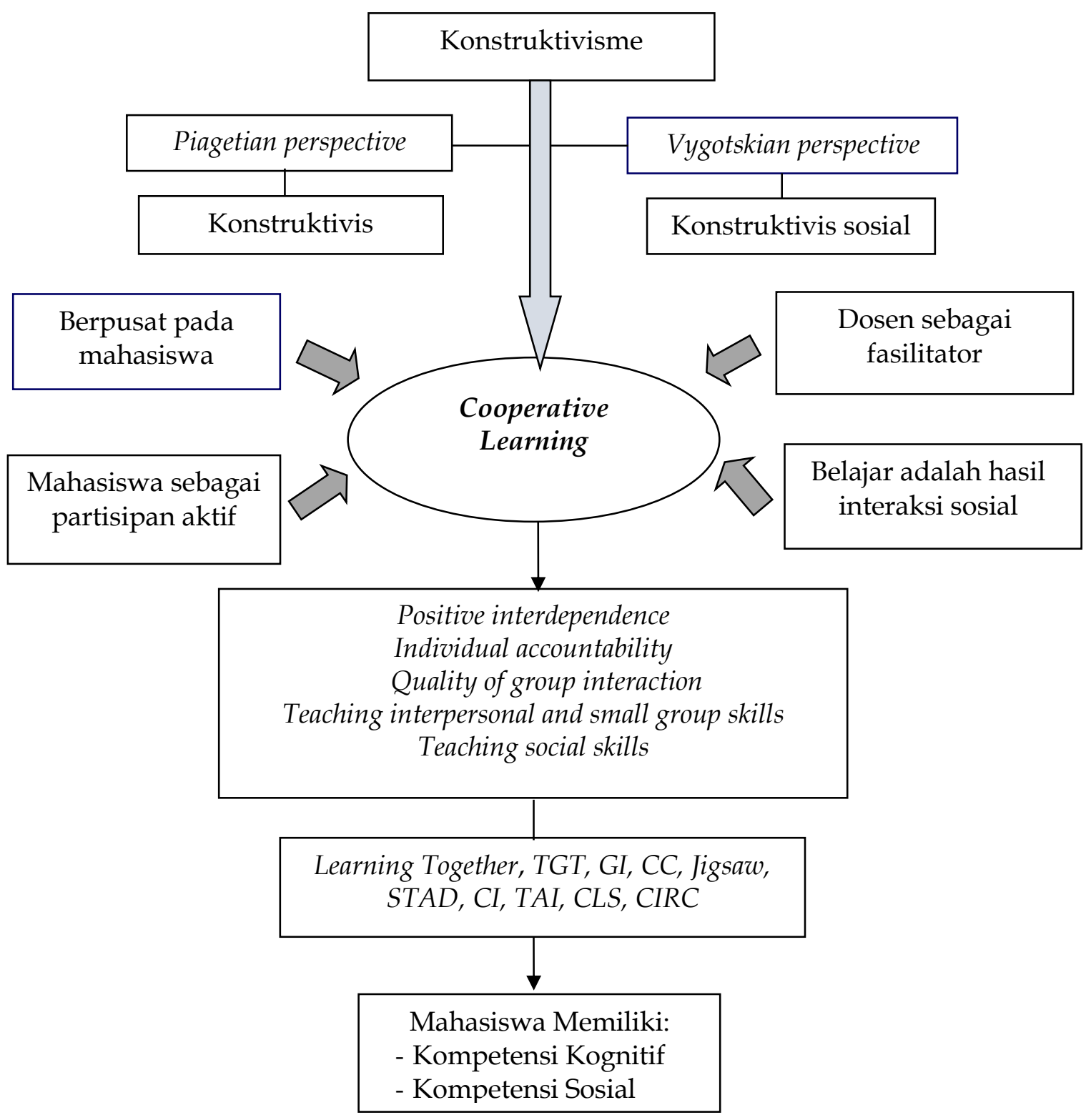

Gambar 2. Model Cooperative Learning untuk Pendidikan Tinggi

Prinsip cooperative learning mesti diterapkan ketika merancang Rencana Pembelajaran Semester (RPS), Satuan Acara Perkuliahan (SAP), materi ajar, dan alat evaluasi yang digunakan. Di samping itu, prinsip cooperative learning juga diperhatikan dalam mengorganisir peran mahasiswa dan dosen, struktur kelompok dan tugas. 
Rencana Pembelajaran Semester (RPS) untuk pendidikan tinggi dengan model cooperative learning memiliki karakteristik sebagai berikut. Pertama, pendekatan yang digunakan adalah process-oriented syllabuses yaitu silabus yang fokusnya pada pengalaman belajar. Jenis silabus yang digunakan adalah procedural syllabuses dan taskbased syllabuses. Kedua, konten dalam silabus dirancang melalui analisis kebutuhan untuk mengakomodasi unsur kebahasaan dan keterampilan dengan merumuskan unsur tersebut dalam indikator tiap KD dan dalam materi pembelajaran.

Demikian juga Satuan Acara Perkuliahan (SAP) untuk pendidikan tinggi dengan model cooperative learning memiliki karakteristik. Pertama, SAP yang dikembangkan menguraikan secara rinci pada komponen kegiatan pembelajaran yang menggambarkan dengan jelas proses pemelajaran kooperatif sesuai dengan metode kooperatif yang digunakan. Kedua, SAP juga mencantumkan materi pembelajaran yang sesuai dengan karakteristik metode kooperatif yang dipilih. Ketiga, SAP menjelakan sumber-sumber belajar yang bisa digunakan. Keempat, SAP memuat rubrik penilaian untuk aspek akademik dan sosial. Kelima, SAP menguraikan pembagian waktu secara jelas untuk setiap tahap pemelajaran kooperatif agar penggunaan waktu menjadi efektif.

Materi ajar perkuliahan untuk pendidikan tinggi dengan model cooperative learning memiliki karakteristik, yakni materi pembelajaran dilakukan oleh dosen dan/atau mahasiswa, materi dapat berupa teks atau online sources, dan desain materi disesuaikan dengan metode kooperatif yang dipilih.

Selain itu, alat evaluasi pembelajaran untuk pendidikan tinggi dengan model cooperative learning juga memiliki karakteristik. Pertama, alat evaluasi yang dikembangkan terdiri dari alat evaluasi untuk aspek akademik dan aspek sosial. Kedua, alat evaluasi yang dikembangkan terdiri dari alat evaluasi untuk individu dan kelompok. Ketiga, alat evaluasi dapat berupa tes, lembar observasi, angket komunikasi kelompok, maupun portofolio. Keempat, alat evaluasi yang digunakan tentunya harus sesuai berdasarkan metode pemelajaran kooperatif yang telah di laksanakan. Kelima, evaluasi bisa dilakukan dengan self-assessment, peer assessment, maupun teacher assessment.

Peran dan tanggung jawab mahasiswa dan dosen dengan model cooperative learning, yakni seluruh mahasiswa terlibat dalam suatu kelompok yang terstruktur. Mahasiswa aktif dan terlibat penuh dalam kerja kelompok, diskusi, debat, tutor, dan kerjasama tim. Adapun tanggung jawab mahasiswa, yakni bekerjasama, mendengarkan, mempertanyakan, menyimpan catatan pekerjaan dan kemajuan, menghasilkan produk, dengan asumsi tanggung jawab pribadi atas perannya dalam kelompok. Pembelajaran dilakukan melalui kegiatan interaksi sosial yang terstruktur, mahasiswa belajar dalam kelompok-kelompok kecil 2-6 orang. Ukuran kelompok yang kecil bertujuan agar setiap anggota berpartisipasi dan berkontribusi terhadap kelompoknya. Setiap mahasiswa dalam kelompok saling membantu satu dengan yang lain secara positif untuk mewujudkan tujuan bersama. Dalam kelompok, mahasiswa menggunakan keterampilan bekerjasama secara kooperatif, seperti keterampilan 
memimpin, dan mengambil keputusan. Setiap mahasiswa dalam kelompok betanggungjawab atas pembelajaran dan pekerjaan sendiri serta pembelajaran dan pekerjaan rekan satu kelompoknya, setiap mahasiswa dalam kelompok dinilai dan menilai kualitas pekerjaan yang telah diselesaikan dan sejauh mana keberhasilan dalam pekerjaan tersebut. Dosen sebgai fasilitator, pelatih, dan pemandu, serta tanggung jawab dosen adalah menyiapkan tugas yang terstruktur, menyiapkan aturan kerja kelompok, menyediakan bahan, memastikan tanggung jawab (peran) individu mahasiswa dan kelompok, memonitor perilaku, intervensi bila diperlukan, membantu, dan memberi penghargaan.

Struktur kelompok dan struktur tugas dengan model cooperative learning meliputi struktur tugas, struktur tujuan, dan struktur penghargaan (reward) yang kooperatif. Struktur tugas mengacu kepada organisasi kerja (peran dan tanggung jawab anggota) dalam kelompok, struktur tujuan mengacu kepada orientasi kelompok dalam mencapai tujuan (prestasi dan keberhasilan kelompok), struktur penghargaan mengacu pada prestasi kelompok sebagai prestasi dan keberhasilan setiap anggotanya, bukan ditentukan oleh anggota tertentu.

Ketika cooperative learning digunakan untuk pembelajaran dalam perkuliahan, maka terdapat sejumlah aspek yang perlu diperhatikan. Metode cooperative learning yang digunakan tergantung kepada karakteristik materi dan mahasiswa. Tujuan, materi, dan evaluasi tidak hanya terkait dengan konten materi tetapi juga keterampilan sosialnya. Dengan demikian, kedua aspek tersebut dicantumkan dalam tujuan, diorganisasikan dalam materi, diajarkan melalui metode kooperatif, dan dievaluasi dari aspek proses dan hasilnya. Dari aspek mahasiswa perlu diperhatikan pengetahuan dan minat mereka, sedangkan untuk pengorganisasian, mahasiswa diorganisir dalam kelompok, materi diorganisir sesuai dengan metode kooperatif yang digunakan, dan lingkungan diorganisir agar mendukung cooperative learning.

\section{SIMPULAN}

Pembelajaran dengan menekankan cooperative learning tepat digunakan untuk membentuk kemampuan kognitif dan keterampilan sosial mahasiswa secara bersamaan. Penerapan pembelajaran dengan menekankan cooperative learning menuntut kesiapan dosen dalam segala hal, seperti kesiapan bahan, kesiapan lingkungan belajar, dan kesiapan alat evaluasi. Sebelum menerapkan model pembelajaran ini, dosen diharapkan mempersiapkan perangkat pendukung tersebut. Dengan kata lain, kemampuan dosen, partisipasi mahasiswa, ketersediaan sumber belajar, dan kelengkapan sarana pendukung merupakan hal-hal pokok untuk penerapan cooperative learning pada pendidikan tinggi.

\section{DAFTAR PUSTAKA}

Apple, M. T. (2006). Language Learning Theories and Cooperative Learning Techniques in the EFL Classroom. Doshisha Studies in Language and Culture, 9(2), 277-301. 
Arends, R. I., \& Kilcher, A. (2010). Teaching for Student Learning: Becoming an Accomplish ed Teacher. Teaching for Student Learning: Becoming an Accomplished Teacher. New York: Routledge. https:/ / doi.org/10.4324/9780203866771

Basta, J. (2011). The Role of the Communicative Approach and Cooperative Learning in Higher Education. Linguistics and Literature, 9(2), 125-143.

Kagan, S., \& Kagan, M. (2009). Kagan Cooperative Learning. San Clemente, CA: Kagan Publishing.

Kurnia, R. D., Ruskan, E. L., \& Ibrahim, A. (2014). Pengembangan Model Pembelajaran Berbasis Cooperative Learning dalam Meningkatkan Motivasi Belajar Mahasiswa dan Peningkatan Mutu Lulusan Alumni Fasilkom Unsri Berbasis E-Learning (Studi Kasus: Mata Kuliah Pemrograman Web) 1,2,3. Jurnal Sistem Informasi (JSI), 6(1), 645-654. Retrieved from https://media. neliti.com/media/publications/130722-ID-pengembangan-model-pembelajar an-berbasis.pdf

Lestari, B. (2008). Peningkatan Kualitas Pembelajaran dengan Model Pembelajaran Cooperative Learning. Jurnal Ekonomi \& Pendidikan, 5(2), 145-153.

Manullang, R., Rahmadana, M. F., \& Putriku, A. E. (2017). Pengembangan Model Pembelajaran Berbasis Kooperatif. Jurnal Niagawan, 6(2), 65-73.

Marashi, H., \& Baygzadeh, L. (2010). Using Cooperative Learning to Enhance EFL Learners' Overall Achievement. IJAL, 13(1), 73-98.

Nangle, D. W., Grover, R. L., Holleb, L. J., Cassano, M., \& Fales, J. (2010). Defining Competence and Identifying Target Skills. In D. W. Nangle, D. J. Hansen, C. A. Erdley, \& P. J. Norton (Eds.), Practitioner's Guide to Empirically Based Measures of Social Skills. New York: Springer.

Nauert, R. (2011). Learning Social Skills in College Helps Predict Work, Career Success.

Rahmadani, Y., Tayeb, T., \& Baharuddin. (2018). Modul Matematika Berbasis Model Kooperatif Tipe STAD dengan Metode Penemuan Terbimbing Pada Pokok Bahasan Teorema Phytagoras. Lentera Pendidikan, 21(1), 23-32.

Richards, J. C., \& R. Schmidt. (2010). Longman Dictionary of Language Teaching and Applied Linguistics; Fourth Edition. Edinburgh Gate: Pearson.

Shaaban, K., \& Ghaith, G. (2005). The Theoretical Relevance and Efficacy of Using Cooperative Learning in the ESL/EFL Classroom. TESL Reporter, 38(2), 14-28.

Thu'aimah, R. A., \& Al-Naqah, M. K. (2006). Ta'lim al-Lughah Ittishaliyyan Baina alManahij wa al-Istiratijiyyat. Rabath: ISESCO. 